\title{
CONSIDERACIONES RESPECTO DEL DERECHO HUMANO A LA IGUALDAD JURÍDICA EN EL TÍTULO SÉPTIMO DE LA LEY FEDERAL DEL TRABAJO
}

\author{
Considerations Regarding The Human Right To Legal Equality \\ In Title Seven Of The Federal Labour Act
}

\author{
Adrián DE LA ROSA ESCALANTE* \\ Rodrigo SERRANO CASTRO**
}

\begin{abstract}
Sumario:
I. Introducción II. Atisbo histórico de la Igualdad jurídica laboral en México III. Principios, normas y garantías IV. El Principio de Igualdad Jurídica Laboral en la Constitución Mexicana y en la Convencionalidad V. Igualdad Formal o en el texto de la Ley VI. Igualdad ante la Ley y sus impactos directos, indirectos y remotos VII. Prohibición de discriminación; a) la restricción, b) discriminación directa o indirecta; $y$ c) discriminación estructural VIII. Criterios de Objetividad y Razonabilidad IX. Conclusiones
\end{abstract}

Resumen. Este trabajo es un análisis de la igualdad jurídica contenida en el texto de la Ley Federal del Trabajo en vigor, que abre con un atisbo breve de su evolución. El estudio de la igualdad jurídica se funda en su naturaleza de derecho humano y por ello se conceptualiza en principios, normas y garantías, razón por la cual su análisis se visualiza desde la perspectiva de la Constitución mexicana y desde la convencionalidad como bloque de constitucionalidad; seguidamente se hace referencia a la igualdad jurídica desde su dimensión sustantiva; a) Igualdad formal o en el texto de la ley, b) Igualdad ante la ley, con sus efectos directos, indirectos y remotos con los que se hace visible actualmente; posteriormente se aborda el concepto más aceptado de discriminación como prohibición y se identifica en el análisis en sus formas de a) restricción, b) discriminación directa y c) discriminación estructural. Para el desenlace se analizan como sustento jurídico los criterios de objetividad y razonabilidad, para finalizar con la conclusión.

Palabras clave: Igualdad formal, igualdad jurídica ante la ley, restricción, discriminación directa, discriminación estructural, criterio de objetividad, criterio de razonabilidad.

Abstract: This paper is an analysis of the legal equality contained in the text of the Federal Labour Act in vigour, which opens with a brief overview of its evolution. The study of legal equality is based on its nature as a human right and is therefore conceptualized in terms of principles, rules and guarantees, which is why its analysis is viewed from the perspective of the Mexican Constitution and from that of conventions as a block of constitutionality; reference is then made to legal equality from its substantive dimension; (b) Equality before the law, with the direct, indirect and remote effects with which it is currently made visible; the most widely accepted concept of discrimination is then addressed as a prohibition and identified in the analysis in its forms of (a) restriction, (b) direct discrimination and (c) structural discrimination. For the outcome, the criteria of objectivity and reasonableness are analysed as a legal basis, and the conclusion is drawn.

* Maestro en Derecho por la UABCS y candidato a Doctor por la Universidad Autónoma de Baja California Sur.

** Doctor en Derecho por la UNAM, Profesor-Investigador de tiempo completo definitivo Titular B, del Departamento de Ciencias Sociales y Jurídicas de la UABCS. 
Keywords: Formal equality, legal equality before the law, restriction, direct discrimination, structural discrimination, objectivity criterion, reasonability criterion.

\section{Introducción}

El desarrollo económico sustentable de México se encuentra revestido de aspectos normativos que sirven de nutriente pragmática para la consolidación institucional, cuya fuente de derecho interna tiene su fundamento en $\operatorname{los}$ artículos $1^{\circ}, 4^{\circ}, 5^{\circ}, 25^{\circ}, 26^{\circ}, 31-\mathrm{IV}$ y $123^{\circ}$ de la C.P.E.U.M (en adelante la Constitución); como fuente de derecho internacional los artículos $1^{\circ} .1$ y $24^{\circ}$ de la Convención Americana Sobre Derechos Humanos (en adelante la Convención) y el Protocolo de San Salvador (en adelante el Protocolo o el Protocolo de San Salvador) en sus artículos $1^{\circ}, 2^{\circ}$, $3^{\circ}, 4^{\circ}, 5^{\circ}, 6^{\circ}, 7^{\circ}$, y $8^{\circ}$, razón por la que el derecho del trabajo es considerado un derecho preferente, al ser origen de otros derechos humanos que, en suma, tributan a la dignidad humana.

En ese tenor el derecho humano al trabajo se debe caracterizar por garantizar, sin restricciones, limitaciones o cualquier otra forma de discriminación, estabilidad laboral duradera con dignidad al trabajo socialmente útil o de calidad de los operarios y es deber del Estado promover su expansión sistemática para cubrir, bajo el manto de esa protección constitucional, a la población económicamente activa y a los beneficiarios de esta. La formalización del trabajo, entonces, permite el acceso al operario, y desde luego a sus beneficiarios, a otros derechos humanos como lo son el acceso a la salud, a la educación continua para y en el trabajo, vivienda, coberturas de incapacidad, retiro, etcétera, que en su conjunto se suman con otros elementos como el salario, para constituir el mínimo vital indispensable para llevar dignidad al trabajador y a su familia.

El estudio de la igualdad jurídica se funda en su naturaleza de derecho humano y por ello se conceptualiza en principios, normas y garantías, razón por la cual su análisis se visualiza desde la perspectiva de la Constitución mexicana y desde la convencionalidad como bloque de constitucionalidad; es, desde luego, un filtro al que toda norma jurídica que se precie de serlo se debe someter, para asegurar el debido control de contenido de la norma, atribuible al poder legislativo, lo que en el peor de los casos puede dar lugar a la identificación de categorías sospechosas susceptibles de institucionalizar la desigualdad.

La desigualdad según la Corte Interamericana de Derechos Humanos, en adelante la Corte $\mathrm{IDH}$, la concibe como contraria a la obligación positiva adquirida por los Estados parte de la Convención y que se precisa en el artículo 1.1, así como del Principio de Igualdad contenido en el artículo 24, los cuales deben de concebirse como una norma general para todo el contenido del tratado. En este sentido, la desigualdad posiciona a unos destinatarios de la misma norma, en condición de vulnerabilidad, respecto de otros destinatarios conceptualmente iguales, otorgándoles en el texto de la Ley tratamientos diferenciados sin justificación constitucional, los cuales son identificables mediante el análisis de objetividad y razonabilidad.

Desde luego se hace referencia a la igualdad jurídica desde su dimensión sustantiva: a) Igualdad formal o en el texto de la Ley y, b) Igualdad ante la Ley, con sus efectos directos, indirectos y remotos con los que se hace visible mediante su implementación; posteriormente se aborda el concepto más aceptado de discriminación como prohibición y se identifica en el análisis en sus formas de a) restricción, b) discriminación directa y c) discriminación estructural. Para el desenlace se analizan como sustento jurídico los criterios de objetividad y razonabilidad, para finalizar con la conclusión. 


\section{Atisbo histórico de la igualdad jurídica laboral en México}

Históricamente, México ha vivido distintos procesos en búsqueda de su organización social sin lograr, como producto de ellos, hacer visibles de forma sostenible a los trabajadores que, antes y después de la República, han estado ahí como pieza fundamental del desarrollo económico nacional. Estuvieron ahí invisibles en el campo, las minas, las comunicaciones terrestres, marítimas y en el comercio, el desarrollo de las innovaciones de la época, para la consumación de la Constitución de 1857 y también para germinar la noción de derecho social en la constitución de 1917 y, por supuesto, en los años posteriores a la promulgación de la constitución vigente.

El desarrollo estabilizador o milagro mexicano (1940-1970) se caracterizó por la industrialización del país, la industria pesada se potencializó en su crecimiento (minería, petróleo, petroquímica, altos hornos, azufrera panamericana, ferrocarriles nacionales, luz y fuerza del centro, etcétera) al igual que la transformación de las materias primas (tabaco, café, azúcar y gramíneas), naciendo en este auge industrial y como necesidad normativa, la Ley Federal del Trabajo vigente (Ley Federal del Trabajo de 1970).

A la sombra de aquella gran industria, crecieron también los grandes sindicatos nacionales de industria y, bajo su brazo, los también grandes contratos colectivos de trabajo, acompañados de lo que se llamó corporativismo sindical, un control político sui géneris del Estado, porque toda aquella industria detentaba un común denominador; era propiedad del Estado mexicano y a través de este mecanismo sustentado por el sindicalismo oficial se aseguraban la exclusividad de cuotas de representación en el Congreso de la Unión para vigilar principalmente la inamovilidad de todo el entramado legislativo y esta conveniente relación sindicalismo corporativoEstado.

Sin embargo, desde 1970 hasta nuestros días, la descomposición de ese modelo de economía cerrada sustentado en la dependencia de la industria estatal y del corporativismo sindical, no solo ha demostrado su inviabilidad al paso del tiempo, sino que ha marcado una clara tendencia negativa en el poder adquisitivo, por un lado, de los operarios, quienes junto con sus beneficiarios han visto mermada generacionalmente su dignidad humana por ser, en lo cotidiano, insuficiente el resultante legislativo de mínimo vital del operario; en tanto que, paralelamente, también se ha marcado una tendencia negativa respecto del anhelado éxito de los empleadores quienes en su gran mayoría no encuentran forma de estabilizar la existencia de sus fuentes de empleo, por los recurrentes impactos derivados principalmente de las políticas macroeconómicas de los gobiernos en turno.

Y es que la composición de las personas que intervienen en el proceso de producción o prestación de servicios ha cambiado radicalmente desde 1970, hasta el 2019. El Estado dejó de ser empresario y la iniciativa privada ocupa ahora ese lugar en una economía abierta a los mercados globales; así la mediana y gran empresa generan únicamente el 10.1\% del total de los empleos formales y la micro y pequeña empresa genera el $89.9 \%$ del total de los empleos formales del país; no obstante estos datos duros, la legislación vigente y la noción de control político del Estado no solo siguen igual que en 1970, sino que parecen cobrar nueva vigencia en la segunda mitad de 2019; esto para mala fortuna de los nuevos actores que hoy día generan la productividad nacional y sostienen la formalidad en el empleo; nuevos actores que, sin embargo, no 
cuentan con representación camaral de peso, y como se verá, tampoco cuentan con un marco normativo adecuado en la legislación vigente, a pesar que generan el 52\% del PIB nacional ${ }^{1}$.

Existen voces especializadas que aseguran que el Estado debe impulsar a las Mipymes dándoles facilidades para que puedan exportar, sin embargo, el propio Estado ha encontrado dificultades para encuadrar las diferencias entre estos tipos de empresas - lo cual es explicable debido a la parcialización del análisis por decantamiento hacia la proporcionalidad fiscal- olvidándose de la visión de interdependencia de los principios constitucionales contenida en los artículos $1^{\circ}, 4^{\circ}, 5^{\circ}, 25^{\circ}, 26^{\circ}, 31$-fracción IV y $123^{\circ}$, que dan vida al principio de desarrollo sustentable, del derecho humano al trabajo digno y de calidad con igualdad jurídica, sustentada en el ius cogens vinculante, de la obligación del Estado de respetar los derechos y libertades reconocidos en la Convención Americana para los Derechos Humanos y de garantizar su libre y pleno ejercicio, sin discriminación alguna. Y por otro lado, hacer efectivo en su régimen jurídico interno el principio de igualdad ante la ley de todas las personas, por lo que estas tienen derecho a igual protección tanto en el texto de la ley, como frente a los actos de autoridad, implementación de políticas públicas, inclusión en la planeación democrática y en los planes y programas de la administración pública.

\section{Principios, normas y garantías}

La revolución francesa ha sido un hito en el reconocimiento universal y constitucional de la igualdad, México la reconoce desde luego en su Constitución no solo como un principio, sino como un derecho humano ${ }^{2}$, en tal sentido, los contenidos de los artículos $2^{\circ}$, apartado B y artículo $4^{\circ}$, párrafo primero, son aceptados en tanto que protegen no solo a personas sino a grupos sociales con la finalidad de proveerlos de igualdad jurídica, no solo en su dimensión formal o de derecho, sino en la sustantiva o de hecho. Especialmente en el contenido del párrafo primero del artículo $1^{\circ}$ de la Constitución, al reconocer a todas las personas como titulares de los derechos humanos, conforme a su naturaleza jurídica. Lo que no solo es acorde con el contenido del artículo 1.2 de la Convención, sino que la supera en la obligación de respetar los derechos humanos al reconocerla también con ciertos límites para las personas jurídicas.

En este sentido, el principio de progresividad es aplicable a todos los derechos humanos y, por ello, a los derechos económicos, sociales y culturales; de hecho, nace originalmente con estos últimos y conforme al texto del artículo $1^{\circ}$ constitucional. Hoy se extiende a todos los derechos humanos individuales y colectivos pues establece claramente que todas las autoridades en el ámbito de sus competencias tienen por obligación proteger, garantizar, promover y respetar los derechos humanos.

Es importante destacar que tanto derechos individuales como colectivos, todos tutelan valores jurídicos básicos derivados de los principios fundamentales de autonomía, igualdad y dignidad; pero es inequívoco que en cada caso es necesario que el Estado provea tanto de garantías normativas como de garantías institucionales; es decir, por una parte el aparato legislativo y por otro, órganos eficaces de implementación e instituciones que aseguren su vigencia.

Es indudable también que, tratándose de la salvaguarda de todos los derechos humanos, el legislativo en México ha hecho su papel creando la norma que los reconoce e impone la obli-

\footnotetext{
1 IMCO. Instituto Mexicano para la Competitividad. A.C.

2 Tesis 1a./J125/2017, SJF y su Gaceta Libro 49, Décima época, Primera Sala, Tomo I., diciembre de 2017, pág. 121. Número 2015679, Jurisprudencia Constitucional, Texto: Derecho Humano a la Igualdad Jurídica. Reconocimiento a su dimensión sustantiva o de hecho en el ordenamiento jurídico mexicano.
} 
gación a todas las autoridades en sus distintos niveles de competencia para que los protejan, garanticen, promuevan y respeten en los términos en que han sido reconocidos en el derecho interno, pero también como han sido reconocidos en el derecho internacional, a través de la suscripción de tratados, convenciones, membresías y otros protocolos que en suma forman parte del bloque de constitucionalidad; vale la pena cuestionarse entonces si el Estado, por medio de sus instituciones implementadoras, se ha visto mermado en el cumplimiento de este deber y degenera en crisis para promover la protección de la dignidad humana y, por ende, no ha sabido ser en la implementación aquel garante del respeto de la autonomía, igualdad y dignidad, en especial en la fórmula Operario/Empleador, cuando del derecho humano a la igualdad jurídica se trata.

Ya se ha perfilado el fundamento constitucional y convencional materia de estudio y que da vida al derecho a la igualdad jurídica en materia de trabajo ${ }^{3}$. Así nos disponemos también en la legislación secundaria interna - Ley Federal del Trabajo- al análisis del título séptimo denominado "Relaciones Colectivas de Trabajo" misma que será en este sentido y siguiendo las nociones que al respecto nos ha aportado Robert Alexy ${ }^{4}$. Consideraremos a las normas como reglas; en sentido amplio diremos que las reglas conforman un conjunto de principios y reglas dirigidos a regular las conductas que deben observarse, para lo cual establecen también prohibiciones. Así podemos clasificar las normas en principios y reglas.

Ya se dijo que los principios revisten un carácter general, sin embargo, las normas se consideran orientaciones específicas destinadas a inducir una conducta determinada para todos sus destinatarios conceptualizados como iguales. Así, principios y reglas establecen el deber ser, tomando en consideración el alto grado de generalidad de los principios y el alto grado de especificidad de la regla; por tanto, la regla puede ser cumplida o no, atendiendo a su validez, sin sobrepasar los límites de la razonabilidad de los principios.

\section{El principio de igualdad jurídica laboral en la Constitución mexicana y en la convencionalidad}

La Constitución mexicana reconoce en su artículo primero, con máxima expresión de igualdad, como titulares de todos los derechos y libertades contenidos en ella, a todas las personas. Asimismo, reconoce, en el artículo $4^{\circ}$, paridad entre el hombre y la mujer y protege a los grupos sociales más vulnerables respecto de los demás miembros de la sociedad mexicana; en el artículo $5^{\circ}$, reconoce la libertad para elegir dedicarse a la industria, comercio, profesión o trabajo que le acomode a cada uno, a condición de que sea lícito; reconoce, en el artículo $25^{\circ}$, al Estado como rector del desarrollo económico integral y sustentable que fortalezca el régimen democrático por medio de la competitividad el crecimiento económico y el empleo, así como una más justa distribución de la riqueza; el artículo $26^{\circ}$, reconoce como obligación positiva del Estado mexicano el diseño incluyente y democrático del Plan Nacional de Desarrollo, así como el diseño de políticas públicas y programas sociales de gobierno; reconoce en el artículo 31, fracción IV, como una obligación de los mexicanos, la de contribuir para el desarrollo económico nacional y en su artículo $123^{\circ}$ establece al trabajo como un derecho para todas las personas, en condicio-

\footnotetext{
3 Artículos $1^{\circ}, 4^{\circ}, 5^{\circ}, 25^{\circ}, 31-I V$ y $123^{\circ}$ de la CPEUM, así como 1.1; 24 de la CADU y artículos $1^{\circ}$ a $8^{\circ}$ del Protocolo Adicional a la Convención Americana sobre Derechos Humanos en materia de Derechos Económicos, Sociales y Culturales "Protocolo de San Salvador".

4 Alexy, Robert (1993), Teoría de los Derechos Fundamentales.
} 
nes de dignidad, el cual debe ser socialmente útil o de calidad, para lo cual, en la Ley, se deberá promover la creación de empleos y la organización social del trabajo.

En la Convención, el Estado mexicano ha reconocido en el artículo 1.1, como una obligación positiva, la de no discriminar a sus gobernados; y en el artículo 24 la de proporcionar un tratamiento de igualdad jurídica a los mismos destinatarios conceptuales de las normas en su derecho interno.

En el Protocolo Adicional a la Convención Americana sobre Derechos Humanos en materia de Derechos Económicos, Sociales y Culturales, "Protocolo de San Salvador", el Estado mexicano se ha obligado, en el artículo $1^{\circ}$, a tomar medidas en su régimen interno a fin de lograr progresivamente y conforme a su legislación, la plena efectividad de los derechos que se reconocen en el protocolo; en el artículo $2^{\circ}$ se ha obligado a adoptar nuevas disposiciones en su derecho interno respecto de aquellas que no garanticen la efectividad de los derechos reconocidos en el protocolo; en el artículo $3^{\circ}$ se ha obligado a no discriminar, haciendo efectivos todos los derechos contenidos en el protocolo para todas las personas destinatarias de las norma; en artículo $4^{\circ}$ se ha obligado a no admitir restricciones a sus destinatarios de ninguno de los derechos reconocidos en su legislación interna o convenciones; en el artículo $5^{\circ}$ se ha comprometido a que el alcance de las restricciones únicamente podrá ser válidas cuando se preserve el interés general dentro de una sociedad democrática, siempre que no contradigan su propósito y razón; en su artículo $6^{\circ}$ se reconoce el derecho al trabajo para todas las personas, como el medio para llevar una vida digna y decorosa, a través del desempeño de una actividad libremente escogida; en su artículo $7^{\circ}$ se reconoce el mismo derecho para todas las personas a gozar de condiciones justas, equitativas y satisfactorias, garantizando en igualdad las condiciones generales de trabajo y prestaciones; y se ha obligado en el artículo $8^{\circ}$ a garantizar el derecho libre a la sindicación, el derecho a la huelga y a establecer restricciones y limitaciones, solo por cuanto sean para salvaguardar el orden público, la protección de la moral, la salud públicas y los derechos y libertades de los demás. Exceptuando a los miembros de las fuerzas armadas, las policías, así como los servidores públicos de las dependencias que presten servicios esenciales para el orden general de la población.

\section{Igualdad formal o en el texto de la Ley}

Para efectos de establecer la materia de estudio se ha significado solo conceptualmente a la igualdad formal o de derecho, respecto de la igualdad sustantiva o de hecho, sin embargo, debe decirse también que ambas son tan complementarias como interdependientes. Por tanto, solo conceptualmente distinguiremos a ambas, por lo que respecto de la igualdad formal se destina contra tratos arbitrarios y la estudiaremos en dos vertientes, a saber: a) Igualdad ante la Ley y, b) Igualdad en el texto de la Ley.

En el caso de la modalidad sustantiva o de hecho, la igualdad consiste en hacer alcanzable para todas las personas destinatarias de la norma, una paridad de oportunidades en el goce y ejercicio real y efectivo de los derechos humanos; en estos caso se logra removiendo o disminuyendo ciertos obstáculos de tipo social, político, cultural, económico o de cualquier otra índoles

5 Debe entenderse en el concepto obstáculos de cualquier otra índole como una fórmula no limitativa, sino más bien ampliable a cualquier otra forma que obstaculice el acceso al goce de los derechos y libertades. 
que haga imposible o dificulte a grupos sociales vulnerables acceder al goce y ejercicio de estos derechos.

Puede decirse entonces que existe violación al principio de igualdad jurídica en su modalidad sustantiva, cuando se identifica una forma de discriminación estructural en contra de uno o más grupos sociales o de uno o más de sus integrantes considerados individualmente ${ }^{6}$ y a pesar de ello, la autoridad no lleva a cabo las acciones necesarias para eliminar o revertir la materia de la discriminación.

La igualdad formal o en el texto de la ley se logra mediante el control de contenido de la norma jurídica, en la cual, el contenido del articulado guarda proporcionalidad, razonabilidad y objetividad respecto de los principios generales contenidos en el bloque de constitucionalidad; es decir, no solo se corresponden, sino que guardan entre sí congruencia y lógica jurídica capaz de superar cualquier análisis de proporcionalidad.

\section{Igualdad en el texto de la Ley y sus impactos directos, indirectos y remotos}

La igualdad ante la Ley se concibe como una uniformidad en la implementación de la norma jurídica por parte de las autoridades jurisdiccionales, ante los actos de autoridad o ante la implementación de políticas públicas, como consecuencia de una planeación incluyente y democrática. En tanto que la igualdad en el texto de la Ley, que interesa a la autoridad materialmente legislativa y que tiene como propósito el control de contenido de la norma jurídica, tiene la finalidad de que el contenido sea diseñado con ausencia de diferenciaciones carentes de justificación en el bloque de constitucionalidad o que violen en sentido amplio el principio de proporcionalidad.

Cuando concurre la violación de esta última vertiente del derecho humano a la igualdad jurídica, es decir, en el texto de la Ley, nos encontramos ante la presencia de actos discriminatorios directos ${ }^{7}$. Puede decirse entonces que se institucionaliza la discriminación, pues se reconoce en el texto de la Ley, para que sea implementada por todas las autoridades administrativas y jurisdiccionales, con sus consecuentes efectos permitidos o así tolerados.

Es aquí donde verteremos el estudio sobre el título séptimo de la Ley Federal del Trabajo en vigor, conocido como de las relaciones colectivas de trabajo, para determinar si existen categorías sospechosas ${ }^{8}$ que establezcan en el contenido de la Ley diferenciaciones legislativas entre la contratación colectiva que es exclusiva de los sindicatos de trabajadores que son titulares de un contrato colectivo de trabajo o contrato Ley; respecto de la contratación individual, que es a la que generalmente tienen acceso los trabajadores de las micro y pequeñas empresas, que, según el punto 5 del cuadro supra líneas, representan el 99.6\% del total de las fuentes de empleo formales del país y cuyos trabajadores se contratan de esa manera por haber decidido libremente no incorporarse a ningún sindicato de trabajadores; ergo, al no formar parte de un colectivo, se contratan de manera individual, porque así se encuentra permitido en el diseño legislativo vigente.

\footnotetext{
${ }^{6}$ Caso Mininuma. EL CASO "MININUMA": UN LITIGIO ESTRATÉGICO PARA LA JUSTICIABILIDAD DE LOS DERECHOS SOCIALES Y LA NO DISCRIMINACIÓN EN MÉXICO, UNAM, Revistas UNAM, Revista de la Facultad de Derecho de México, Tomo LXIX, Número 274 (mayo-agosto 2019).

7 Cuando la norma tiene la apariencia de neutra, pero sus resultados inducen a una diferenciación de tratos o exclusión desproporcionada de cierto grupo social sin que exista una justificación objetiva para ello, se encuentra bajo la presencia de actos discriminatorios indirectos.

8 Relativas al último párrafo del artículo $1^{\circ}$ de la Constitución
} 


\section{LA OBLIGACIÓN DE CELEBRAR POR ESCRITO EL CONTRATO DE TRABAJO}

Nadie tiene duda que celebrar por escrito el contrato de trabajo ${ }^{9}$ otorga a las partes certidumbre jurídica de los compromisos de las partes contratantes, otorga no solamente certeza, sino claridad y un punto definido jurídicamente de partida para establecer mejoras económicas paralelas a las de certificación de habilidades y mejora continua del trabajador. Es con esta evidencia documental del contrato escrito que las instituciones, tanto de seguridad social como de vivienda y retiro, facilitan al trabajador el acceso a sendos derechos humanos. Pero todo lo contrario sucede cuando al contrato de trabajo individual se le otorga la calidad de presunción legal ${ }^{10}$. Como todos sabemos, la presunción legal queda invariablemente sujeta a prueba. Me pregunto, ¿a quién en su sano juicio se le ocurrió reconocer en ley una categoría jurídica tan despreciable de la dignidad humana? O dicho de otra forma, ¿ Cómo ha sido posible que a lo largo de al menos tres procesos legislativos relevantes ocurridos en la Ley Federal del Trabajo desde la reforma en materia de derechos humanos promulgada el 10 de junio del 2011, haya quedado intocada esta aberrante forma de contratación individual?

En este sentido, este tratamiento normativo diferenciado trasgrede la noción de igualdad a que se refiere el artículo 24 de la Convención Americana para los Derechos Humanos, toda vez que la definición de trabajador es la misma en la Ley para todos los operarios, en tanto que la noción de igualdad se atribuye directamente a la unidad de naturaleza del género humano, siendo por tanto inseparable de la dignidad esencial de persona frente a la que es opuesta o contraria toda circunstancia, que por considerar superior a determinado grupo como en este caso los de contratación colectiva, conduzca a tratarlo con privilegio, o a la inversa que por considerar inferior a los trabajadores de contratación individual, proceda a tratarlos con hostilidad o cualquier otra forma que discrimine a estos trabajadores del goce de derechos que si se le reconocen a otros que no se consideran inmersos en tal situación de inferioridad. Es por ello por lo que no es admisible crear o permitir la existencia de diferencias de tratamiento entre seres humanos que no se correspondan con su única e idéntica naturaleza ${ }^{11}$, pues, en el texto de la ley, trabajador es la persona física que presta a otra física o moral, un servicio personal, subordinado, concepto en el cual no cabe discriminación alguna.

\section{POSIBILIDAD DE CELEBRAR COMISIONES MIXTAS PARA EL CUMPLIMIENTO DE ACTIVIDADES SOCIALES Y ECONÓMICAS}

En el diseño legislativo actual, el artículo 392 de la Ley Federal del Trabajo establece de forma excluyente, como privilegio para la contratación colectiva, la posibilidad de celebrar comisiones mixtas para el cumplimiento de actividades sociales y económicas; de esta forma la asamblea, por conducto de sus representantes legales sindicales, tiene la posibilidad de conformar junto con el patrón, comisiones para profundizar en el ordenamiento de las condiciones generales de

\footnotetext{
9 Artículo 390, 24 y 25 de la Ley Federal del Trabajo.

10 Artículo 21 de la Ley Federal del Trabajo, con relación al párrafo primero del artículo 20 de la misma Ley.

${ }^{11}$ Corte IDH, Propuesta de modificación a la Constitución Política de Costa Rica relacionada con la naturalización, Opinión Consultiva OC-4/84 de 19 de enero de 1984. Serie A No. 4.

En el mismo sentido:

Condición jurídica y derechos humanos del niño. Opinión Consultiva OC-17/02 de 28 de agosto de 2002. Serie A No. 17, párr. 45;

Condición jurídica y derechos de los migrantes indocumentados. Opinión Consultiva OC-18/o3 de 17 de septiembre de 2003. Serie A No. 18, párr. 87.
} 
trabajo, tales como capacitación inicial, certificación de habilidades, educación continua, participación de utilidades, seguridad e higiene, becas, entre otras diversas que permiten no solo una mayor y más efectiva coordinación para la consecución de los objetivos de la empresa, sino que permiten potenciar el nivel de dignidad humana de los trabajadores, inclusive porque al elevar el nivel de productividad y competitividad, se extiende en el tiempo el acceso a mejores niveles de ingreso y por tanto a los derechos humanos que se detonan con el acceso al derecho humano al trabajo, tales como el acceso a la seguridad social para el trabajador y sus beneficiarios, el derecho humano a la vivienda y al sistema de ahorro para el retiro.

Aunque no exista una prohibición expresa en la ley para que estas comisiones puedan celebrarse y tener efectos en la contratación individual, no menos cierto es que no aparece en el texto de la ley como una obligación de las partes, a lo sumo el artículo 25 de la ley, en su fracción VIII, solo establece como una obligación patronal que, el trabajador será capacitado o adiestrado en los términos de los planes o programas establecidos o que se establezcan en la empresa. Lo que como es del dominio público casi nunca es supervisado por las autoridades administrativas del trabajo. Si bien es una obligación patronal pagar las capacitaciones o adiestramientos del trabajador, también es cierto que el capítulo III bis, relativo a la capacitación y adiestramiento de los trabajadores, correspondiente al título cuarto de la ley, relativo a los derechos y obligaciones de los trabadores y de los patrones, resulta especialmente respecto de la micro y pequeña empresas y de sus trabajadores, una disposición no justificada desde el punto de vista del principio de objetividad; pues al arrojarle al patrón la obligación material y financiera de la capacitación y adiestramiento en términos del artículo 153-A; no establece en todo caso el monto de las cuotas que quedarán a cargo del patrón si éste decide adherirse a los sistemas generales que establezca la Secretaría del Trabajo y Previsión Social; pero no siendo así, tampoco se establecen métodos, organismos especialmente diseñados, creados, habilitados y certificados para desahogar con éxito estos procesos, con lo cual el artículo 153-B de la ley carece de objetividad, lo que lo hace oscuro, en especial para las micro y pequeñas empresas que, ante tal, la mayoría de las veces, quedan frente a la autoridad administrativa laboral en indefensión total, y sus trabajadores sin la certeza jurídica de mejorar su dignidad humana en base a la educación contínua o certificación de habilidades.

\section{TABULADOR SALARIAL OBLIGATORIO}

Los artículos 391, fracción VI, 393 y el diverso 399 bis, todos de la Ley Federal del Trabajo, también se encuentran inscritos dentro del capítulo III, relativo a los contratos colectivos de trabajo; correspondiente al título séptimo de la ley, relativo a las relaciones colectivas de trabajo, los cuales exigen la existencia de un tabulador salarial que defina número de trabajadores, categoría y monto del salario, bajo pena de no producir efectos jurídicos el contrato colectivo al que le falte dicha información. El hecho de que el legislativo otorgue un capitulado diferente para tratar un tema que es universal al mismo destinatario que es el trabajador y que ya ha sido tratado en el título tercero, relativo a las condiciones de trabajo, capítulos $\mathrm{V}$, relativo al salario; capítulo VI, relativo al salario mínimo y capítulo VII, relativo a las normas protectoras y privilegios del salario, deja mucho que decir del tratamiento normativo diferenciado, pues en el texto de la ley se reconoce que el trabajador, a pesar de encontrarse definido en su parte sustantiva de manera genérica como la persona física que presta a otra persona física o moral un trabajo personal subordinado, en realidad encuentra en el texto de la ley que en el trabajo contratado de manera individual tiene un tratamiento y en el trabajo contratado de manera colectiva, tiene otro tratamiento diferenciado y más ventajoso; a saber, el artículo 25 de la ley señala en su 
fracción VI como parte del contenido del "escrito" en que constan las condiciones generales de trabajo, la forma y el monto del salario; previamente define en el diverso artículo 82, que salario es la retribución que debe pagar el patrón al trabajador por su trabajo. Asimismo, en el artículo 85 señala que este debe ser remunerador y nunca inferior al fijado como mínimo, seguidamente señala este último artículo, que para fijar el salario se tomará en cuenta la cantidad y calidad del trabajo, lo cual estimamos es una fórmula que cumple con el principio de universalidad, pero también con el principio constitucional de trabajo de calidad, contenido en el artículo 123 y por tanto es aplicable a cualquier forma de contratación, en cualesquiera de sus modalidades reconocidas en Ley; sin embargo, subsiste la inequidad de otorgar un capítulo especial para tratar el tema del salario cuando se trata de la contratación colectiva, donde a diferencia, si establece diversas obligaciones tales como la de revisión anual, la de inserción del tabulador salarial y su registro.

Establecer este tipo de diferencias en el trato legislativo, a nuestro juicio, obligaría al legislador a explicitar los criterios que debe cumplir esta diferencia normativa, para que no sea considerada como un acto discriminatorio. Esto es, una exposición que exprese la objetividad y razonabilidad en que se funda tal diferenciación y cuyo contenido deje claridad respecto del principio de igualdad y no discriminación, pues un tratamiento normativo diferenciado de esta magnitud solo se puede concebir bajo la noción de un carácter fundamental para la salvaguarda de los derechos humanos de todas las personas, en la que siempre debe prevalecer la interpretación más favorable tanto respecto de la norma interna, como de la norma internacional; dicho en otras palabras, y como lo establece el artículo 27 de la Convención de Viena para el derecho de los tratados ${ }^{12}$, relativo al Derecho Interno y la Oservancia de los Tratados (Viena, 23 de mayo de 1969): un Estado parte no puede invocar las disposiciones de su derecho interno como justificante del incumplimiento de un tratado, de la misma forma que si la norma interna es mas progresista que la contenida en el tratado internacional, no puede dejarse sin efectos esta última, máxime que conlleve mayores beneficios en la dignidad humana y aunado a ello se trate de una norma dirigida a los mismos destinatarios, que para este caso lo es el trabajador; con independencia de que en ejercicio de su libertad, escoja pertener o no pertenecer a una asociación sindical.

Es decir, que un trabajador que en ejercicio de su libertad de asociación decide no pertener a un sindicato, no tiene por qué ver disminuida, en el texto de la ley, la posibilidad de mejorar su condición de dignidad humana junto con la de sus beneficiarios. Tal es el caso, que en la contratación colectiva no solo se hace exigible que en el contenido del contrato colectivo se establezca anexo o en el cuerpo del contrato, el tabulador salarial, para que tenga validez el contrato; sino que adicionalmente, se establece la obligación de revisar anualmente o antes, de ser así necesario, el tabulador salarial, para establecerle mejoras, ello desde luego en función de la productividad; privilegio legal del cual el trabajador que libremente decidió no pertenecer a un sindicato no tiene acceso, ni mecanismo legal para negociar incremento alguno en su salario, quedando a la deriva su condición jurídica salarial, a condición de que su retribución no sea inferior al salario mínimo vigente; pues ni siquiera los incrementos a este último le son aplicables en tanto su salario sea mayor al mínimo; condición en la que se encuentra una gran parte de la población

\footnotetext{
${ }^{12}$ Convención de Viena sobre el Derecho de los Tratados, Parte III relativa a la Observancia, aplicación e interpretación de los Tratados, Sección Primera, de la Observancia de los tratados.

Artículo 27. El Derecho interno y la observancia de los tratados. Una parte no podrá invocar las disposiciones de su derecho interno como justificación del incumplimiento de un tratado. Esta norma se entenderá sin perjuicio de lo dispuesto en el artículo 46.
} 
económicamente activa que trabaja en la formalidad y que como ya se dijo antes, representa aproximadamente el $89.9 \%$ del total de los trabajadores formales de México.

\section{REVISIÓN OBLIGATORIA DEL CLAUSULADO DEL CONTRATO DE TRABAJO}

El contenido del primer párrafo del artículo 123 constitucional reza en el sentido de que el trabajo debe ser digno y de calidad o lo que es lo mismo, debe ser socialmente útil. No hay duda que este principio constitucional reconoce al derecho del trabajo, como un derecho inmerso en una dinámica evolutiva, el cual, para ello, necesariamente requiere que tanto las condiciones de trabajo como la capacitación, adiestramiento y certificación de procesos, así como las prestaciones que se retribuyan al trabajador, se sujeten a una planeación en constante revisión bajo esta fórmula dignidad/calidad; lo que sin duda se refleja en el nivel de dignidad del operario y de sus beneficiarios, pero también en el crecimiento de la productividad y competitividad de la fuente de trabajo, así debe ser.

Al mismo tiempo, esta máxima constitucional nada dice respecto de su implementación exclusiva en la contratación colectiva; sin embargo, el legislador restringió de manera privativa para los trabajadores, bajo relaciones colectivas de trabajo, la revisión obligatoria del clausulado del contrato de trabajo, es decir, para el trabajo contratado con un titular sindical, sin establecer fundamento alguno que sustente la razonabilidad u objetividad de esta determinación, que excluye a la contratación individual y que sin duda impacta profundamente en la desigualdad estructural de México $^{13}$ y que se materializa por el simple hecho de ejercitar la libertad de decidir no pertenecer a una organización sindical.

Se estimó que a la luz del artículo primero constitucional, en el cual se establece en su párrafo primero, que en los estados unidos mexicanos todas las personas gozarán de los derechos humanos reconocidos en esta Constitución y en los tratados internacionales de los que el Estado mexicano sea parte, así como de las garantías para su protección, cuyo ejercicio no podrá restringirse ni suspenderse, salvo en los casos y bajo las condiciones que esta constitución establece; no existe justificación alguna para establecer una restricción legislativa de este calado en perjuicio de una enorme mayoría de los destinatarios de esa norma, para privilegiar a unos pocos trabajadores ${ }^{14}$, sino que por el contrario al ser de mayor beneficio para un mayor número de personas - llámese trabajadores contratados en cualquier modalidad individual - no solo se superan progresivamente las disposiciones contenidas en los artículos 7 y 8 del Protocolo de San Salvador ${ }^{15}$, sino que se magnifica su alcance con efecto positivo en la dignidad de millones de

\footnotetext{
${ }^{13}$ Las desigualdades estructurales suponen una condición de vulnerabilidad entre destinatarios de una misma norma, política pública o acto de autoridad, a veces, pero no necesariamente, se caracteriza por una dimensión ideológica; esta vulnerabilidad es mantenida por una condición de iure y de facto, la cual conduce al establecimiento de diferencias de acceso de unos y otros a los recursos públicos administrados por el Estado.

14 De acuerdo con la S. T. y P. S., existen 3, 347 organizaciones sindicales registradas en México, distruidas en 7 confederaciones o centrales obreras, que concentran a poco más de 1 millón 904 mil trabajadores formales. En tanto que hasta el 31 de enero de 2019, se tienen registrados ante el Instituto Mexicano del Seguro Social a 20 millones 174 mil 11 puestos de trabajo. El 85.6\% son permanentes y $14.4 \%$ eventuales.

15 Protocolo Adicional a la Convención Americana sobre Derechos Humanos en Materia de Derechos Económicos, Sociales y Culturales (Protocolo de San Salvador).

Artículo 7. Condiciones justas, equitativas y satisfactorias de trabajo. Los Estados parte, en el presente protocolo, reconocen que el derecho al trabajo al que se refiere el artículo anterior supone que toda persona goce del mismo en condiciones justas, equitativas y satisfactorias.
}

Artículo 8.

1. Los Estados parte garantizarán: 
trabajadores. A mayor abundamiento, no existe justificación razonable, ni objetiva para que los trabajadores contratados individualmente, por el hecho de serlo y con independencia de elegir o no, pertenecer a una asociación sindical, sufran en su dignidad a la par que sus beneficiarios, bajo una restricción en todo caso justificada para las fuerzas armadas, las de policía, al igual que de otros servicios públicos esenciales, que por su naturaleza de indispensables para el interés general de la sociedad, se justifica coptar su derecho a proteger y promover sus intereses, bajo la condición de no pertenecer a un sindicato o de no suspender sus actividades; no así para el trabajador contratado de manera individual que no sufre de esa restricción en el bloque de constitucionalidad ${ }^{16}$.

Tras la lectura del artículo 8, literal b, del Protocolo de San Salvador, vale aquí la pena cuestionarse ¿qué tendría de democrático para nuestra sociedad, que por no pertenecer a un sindicato, se le restrinja el derecho a establecer mejoras en las condiciones generales de trabajo, capacitación, adiestramiento, certificación de habilidades y procesos, así como de sus prestaciones concertadas con el patrón, al trabajador contratado individualmente, mediante la revisión periodica de su contrato, dentro del marco de la Ley? Sin duda que no resulta válido para una sociedad democrática restringir el acceso a la revisión del clausulado del contrato de trabajo al trabajador contratado de manera individual; sería contrario al principio de progresividad y no se estaría garantizando la máxima protección constitucional que otorga el primer párrafo del artículo primero constitucional a trabajadores sobre los que no existe ninguna justificación objetiva ni razonable para que sean segregados en la Ley e impedidos de pactar junto con el patrón, las mejoras necesarias para elevar la dignidad en el trabajo y establecer las condiciones para elevar la calidad y cantidad del producto o servicio que se presta. Indudablemente que de eliminarse esa restricción de facto, se favorecería a estas personas con la protección más amplia y el beneficio sería positivo, inclusive en el desarrollo económico sostenible del cual el Estado funje como rector ${ }^{17}$ (artículo 25 constitucional, D.O.F. 26 de mayo 2015); en tanto que de darse, se estaría garantizando plena efectividad de acceso al derecho humano al trabajo, en especial

El derecho de los trabajadores a organizar sindicatos y a afiliarse al de su elección.

El derecho de huelga.

2. El ejercicio de los derechos enunciados precedentemente solo puede estar sujeto a las limitaciones y restricciones previstas por la Ley, siempre que estos sean propios a una sociedad democrática, necesarios para salvaguardar el orden público, para proteger la salud, o la moral públicas, así como los derechos y las libertades de los demás. Los miembros de las fuerzas armadas y de policía, al igual que los de otros servicios públicos esenciales, estarán sujetos a las limitaciones y restricciones que imponga la Ley.

3. Nadie podrá ser obligado a pertenecer a un sindicato.

${ }^{16}$ Con ello nos referimos a aquellos principios, tratados, protocolos, criterios, softlaw y normas que, sin aparecer formalmente en el texto constitucional, son utilizados o pueden ser utilizados como parámetros del control de constitucionalidad de las leyes, en tanto que se asumen integradas a la Constitución por diversas vías, como por mandato de esta.

17 Constitución mexicana. Artículo 25. Corresponde al Estado la rectoría del desarrollo nacional para garantizar que este sea integral y sustentable, que fortalezca la soberanía de la nación y su régimen democrático y que, mediante la competitividad, el fomento del crecimiento económico y el empleo y una más justa distribución del ingreso y la riqueza, permita el pleno ejercicio de la libertad y la dignidad de los individuos, grupos y clases sociales, cuya seguridad protege esta Constitución. La competitividad se entenderá como el conjunto de condiciones necesarias para generar un mayor crecimiento económico, promoviendo la inversión y la generación de empleo. (Reformado mediante Decreto publicado en el Diario Oficial de la Federación el 5 de junio de 2013). El Estado velará por la estabilidad de las finanzas públicas y del sistema financiero para coadyuvar a generar condiciones favorables para el crecimiento económico y el empleo. El Plan Nacional de Desarrollo y los planes estatales y municipales deberán observar dicho principio. (Adicionado mediante Decreto publicado en el Diario Oficial de la Federación el 26 de mayo de 2015). 
las referidas al logro del pleno empleo a que se refiere el artículo 6, arábigo 2, del mencionado Protocolo.

\section{OBLIGACIÓN DE SUSCRIBIR CONTRATOS NUEVOS A PARTIR DE PRESTACIO- NES VIGENTES EN LA EMPRESA Y NUNCA MENOS}

El artículo 394 de la Ley Federal del Trabajo constituye un monumento al principio de progresividad, al establecer que el Contrato Colectivo de Trabajo no podrá concertarse en condiciones menos favorables para los trabajadores, que las contenidas en contratos ya vigentes de la empresa o establecimiento; este contenido en primer orden establece un respeto a los derechos adquiridos por otros trabajadores o por los que pretenden la suscripción del contrato colectivo, lo cual es correcto y jurídicamente aceptado; en segundo lugar establece la pauta para que en progresividad se establezca un parámetro de control convencional, dicho esto en el estricto sentido de la negociación contractual con el patrón, a partir del cual se puedan analizar el valor de las cláusulas del mismo, en función de la productividad y de la calidad en el trabajo, así como para establecer mejoras en las condiciones de dignidad con que se presta el servicio subordinado. Toda una maravilla que podría estar completa si en el texto de la Ley se extendiese el beneficio a todos los trabajadores, incluidos los de contratación individual.

Para la Corte IDH, la restricción carente de un criterio de razonabilidad y objetividad, contenida así en el texto de la Ley, es una forma de discriminación, ello en términos del contenido del artículo 1.1 de la Convención Americana para los Derechos Humanos; si esta tiene por objeto menoscabar el reconocimiento, goce o ejercicio, en condiciones de igualdad, de los derechos humanos y libertades fundamentales de todas las personas. La Corte considera que el derecho a la igualdad y no discriminación abarca dos concepciones: a) La concepción negativa relacionada con la prohibición de diferencias de trato arbitrarias, y b) La concepción positiva relacionada con la obligación de los Estados de crear condiciones de igualdad real frente a grupos que han sido históricamente excluidos o que se encuentran en mayor riesgo de ser discriminados ${ }^{18}$.

La Corte ha sido enfática en que tratándose de la prohibición de discriminación por una de las categorías protegidas contempladas en el artículo 1.1 de la Convención Americana para los Derechos Humanos, la eventual restricción de un derecho exige una fundamentación rigurosa y de mucho peso, invirtiéndose, además, la carga de la prueba, lo que significa que corresponde a la autoridad demostrar que su decisión no tenía un propósito ni un efecto discriminatorio ${ }^{19}$. En el caso del artículo 394 que se analiza, el legislador no expone principio alguno de derecho en que se acoja dicha disposición restrictiva, pero sí la delimita al contexto jurídico del contrato colectivo, más allá de que, también sin justificación en el bloque de constitucionalidad, se encuentra ubicado el artículo en un título de ley creado exprofeso para este tipo de contratación.

\footnotetext{
${ }^{18}$ Corte IDH. Identidad de género e igualdad y no discriminación a parejas del mismo sexo. Obligaciones estatales en relación con el cambio de nombre, la identidad de género y los derechos derivados de un vínculo entre parejas del mismo sexo (interpretación y alcance de los artículos 1.1, 3, 7, 11.2, 13, 17, 18 y 24, en relación con el artículo 1 de la Convención Americana sobre Derechos Humanos). Opinión Consultiva OC-24/17 de 24 de noviembre de 2017. Serie A No. 24.

${ }^{19}$ Corte IDH. Caso Granier y otros (Radio Caracas Televisión) Vs. Venezuela. Excepciones Preliminares, Fondo, Reparaciones y Costas. Sentencia de 22 de junio de 2015. Serie C No. 293.
} 


\section{POSIBILIDAD DE MODIFICAR LAS CONDICIONES DE TRABAJO}

La búsqueda del equilibrio de la relación obrero patronal puede eventualmente verse afectada tanto por factores internos relativos a desaciertos en la conducción de las políticas de la empresa, o atribuibles a abusos o incumplimientos de parte de los trabajadores; algunas otras ocasiones, se atribuye a factores externos, como la caída del precio del producto o servicio que se oferta, su desuso por quedar sustituido por nuevos productos o servicios, la falta de actualización de tecnologías, entre otros, o inclusive circunstancias poco previsibles como fenómenos naturales, incendios o cuando el costo de la vida impone un desequilibrio entre los factores de la producción, etc. En esos y otros casos similares, siempre es indispensable que la Ley establezca con claridad la posibilidad de establecer modificaciones a las condiciones generales de trabajo previamente contratadas y que se encuentran en vigencia dentro de la empresa o establecimiento con la finalidad de hacer prevalecer por el mayor tiempo posible el derecho humano al trabajo, mediante el extendimieto de la vida de la empresa, garantizando el empleo en las mejores condiciones de dignidad posibles; caso en el cual la Ley le otorga un tratamiento procesal que ha denominado conflicto colectivo de naturaleza económica.

Al efecto, el pleno de la Suprema Corte de Justicia de la Nación se ha apartado del arcaico criterio esgrimido por la extinta Cuarta Sala, por el cual estos conflictos debían resolverse analizados desde un enfoque procesalista; transitando al análisis tutelado por el juzgador consistente en valorar el aspecto económico y de mercado que históricamente rodea a la relación laboral y en especial a un conflicto que de suyo, en origen es económico; ello bajo el análisis de pruebas tales como actualizaciones actuariales, contabilidad, finanzas, productividad, etc., con el propósito de que el juzgador emita nuevas bases obligatorias para las partes — condiciones generales de trabajo- bajo las cuales deberá operar la fuente de trabajo, consiguiendo así superar el estado de crisis económica ${ }^{20}$.

Esta disposición se considera de avanzada sobre todo en el marco de una nación que no puede concebirse aislada en las relaciones comerciales de sus productos y servicios, sino que enclavada en el mercado global y bajo el cumplimiento de tratados comerciales de gran relevancia ${ }^{21}$, así como de compromisos establecidos en foros internacionales, debe fomentar de manera urgente normativas que tiendan a fortalecer el desarrollo económico de sus unidades productivas y de protegerlas de la evolución que el mercado impone en todo aspecto a los bienes y servicios que dan fortaleza a la economía del país, en aras de garantizar el acceso a los derechos humanos, a los trabajadores de estas y a sus beneficiarios.

La relevancia que representa, en la realidad de los datos duros, la diversificación y crecimiento mayoritario, principalmente de la micro y pequeña empresa, deriva de que son responsables de sostener casi el $90 \%$ del empleo formal del país y que aportan el 52\% del producto interno

\footnotetext{
${ }^{20}$ Tesis número 2008792. P. IV/2015 (10a.), Semanario Judicial de la Federación, Gaceta del Semanario Judicial de la Federación. Libro 17, Pleno, Décima Época, abril de 2015, p. 159. Rubro. "CONFLICTOS COLECTIVOS DE NATURALEZA ECONÓMICA. EL AMPARO PROMOVIDO EN CONTRA DEL LAUDO QUE LOS RESUELVE, PERMITE AL JUZGADOR EXAMINAR NO SÓLO LOS ASPECTOS FORMALES DE ESA DECISIÓN, SINO INCLUSO, LA SITUACIÓN ECONÓMICA DE LA EMPRESA ACTORA".

${ }^{21}$ Conforme a los datos de la Secretaría de Economía, México participa en una red de 12 tratados de libre comercio, celebrados con 46 países (el T-MEC es el más medíatico y amplio), 32 acuerdos para la promoción y protección recíproca de las inversiones (APRIS) con 33 países y 9 acuerdos de alcance limitado (solo de complementación económica o de alcance parcial) con la ALADI. Adicionalmente participa en organismos y foros multilaterales y regionales como la OMC (Organización Mundial de Comercio), la OCDE (Organización para la Cooperación y Desarrollo Económicos) y la APEC (Foro de Cooperación Económica Asia-Pacífico).
} 
bruto (PIB) nacional; sin embargo, frente de las sacudidas del mercado interno e internacional son las que más sufren, dada la carencia de un marco normativo integral y especilizado que les permita no solo mayor certeza jurídica, sino extender su promedio de vida y el crecimiento dentro de un marco de mayor igualdad proporcional en el mercado. A falta de ello su promedio de vida se reduce a 7.7 años, con los colaterales efectos para sus trabajadores, a quienes hasta ahora no se les garantiza de manera efectiva la estabilidad en el empleo, debido a que la mayor parte de estas empresas ${ }^{22}$ se ve obligada a cerrar antes de cumplir dos años de vida.

Con estos antecedentes, que le son inmanentes al mercado interno e internacional, el hecho de que exista una norma como la contenida en los artículos 426 y 900 al 919, que permita a los sindicatos de trabajadores y a los patrones solicitar a la autoridad laboral competente la modificación de las condiciones generales de trabajo, previo el análisis económico del mercado, la situación financiera real de la empresa y de su relación con el contenido del contrato colectivo de trabajo, cuando así se justifique. Me parece una normativa de avanzada en la consecusión de preservar no solo el principio de estabilidad en el empleo, es decir, extender en el tiempo el empleo mismo, sino en el objetivo fundamental de extender también en el tiempo para los trabajadores y sus beneficiarios, los derechos humanos que se detonan con el acceso al empleo formal. Solo habría que extender esa posibilidad a todo el universo de empresas generadoras del empleo formal y a sus trabajadores, en cumplimiento al artículo primero, párrafo primero constitucional, es decir, a todas las personas destinatarias de esta norma, para no establecer restricciones sin justificación en el bloque de constitucionalidad.

\section{GARANTÍA PROCESAL PARA SUSPENDER O EN SU CASO, TERMINAR LA RE- LACIÓN DE TRABAJO}

En todo Estado democrático, la garantía procesal por sí misma establece en el texto de la Ley un modo de cumplir con los principios de seguridad jurídica, entre ellos el principio de igualdad ante la Ley, de equidad para asegurar la garantía a sus destinatarios, en fin, robustece el debido proceso, evitando así que el Estado avasalle por acción u omisión, derechos fundamentales de sus gobernados. A este respecto los diversos artículos 427 y 433 de la Ley Federal del Trabajo, otorgan una extraordinaria cobertura cuando de seguridad jurídica se trata en eventualidades tales como en el primer caso, la muerte o estado de interdicción del patrón, el caso fortuito o fuerza mayor no imputable al patrón que traiga como consecuencia inmediata y directa la suspensión de las actividades en la fuente de trabajo; y en el segundo de los casos, la terminación de las relaciones de trabajo como consecuencia del cierre de las empresas o establecimientos o de la reducción definitiva de sus actividades; pues en ambos casos se prevé un procedimiento respecto del cual, tanto la empresa como el sindicato de trabajadores deberá sujetarse para, entre otras cosas, proteger económicamente a los trabajadores.

Este nivel de previsión social en el marco del diseño legislativo, creado en el título séptimo para las relaciones colectivas de trabajo, nos resulta un tratamiento legislativo diferenciado sin justificación alguna en el marco del bloque de constitucionalidad, en especial, porque quienes decidieron libremente no pertenecer a un sindicato y, por ende, son contratados bajo cualquier modalidad de las que ofrece la contratación individual, son despojados de esa seguridad jurídica en los siniestros o eventos previstos de manera exclusiva para los trabajadores contratados colectivamente; de tal suerte que esos trabajadores, en esos casos, no son titulares de la certeza

\footnotetext{
${ }^{22}$ Conforme a la investigación del movimiento del emprendedurismo Fuck Up Nights, sustentado por Amexcap, el 75\% de las startups cierran operaciones luego del segundo año de operaciones.
} 
de, por una parte, volver a ser empleados cuando haya pasado el caso fortuito o fuerza mayor, ni de ser garantizados mediante un salario o indemnización; o por la otra vicisitud, no cuentan con la certeza jurídica de que la empresa se responsabilice de manera inmediata al cierre definitivo o reducción de actividades defitiva, de ser debidamente indemnizados, mediante un protocolo así diseñado y reservado para unos, pero en desventaja de los otros.

A ese respecto, la Corte Interamericana, en sentido amplio, ha establecido que debe considerarse discriminación cualquier restricción de derechos originada por cualquier condición social, que para este caso lo es; ser un trabajador que decidió libremente no pertenecer a un sindicato y que, por tal, no tiene acceso a la contratación colectiva ni a los beneficios del título séptimo de la Ley Federal del Trabajo, y que por ese motivo obtiene de la ley el resultado de anular o menoscabar el reconocimiento, goce o ejercicio, en condiciones de igualdad, de los derechos humanos y libertades fundamentales que sí le son reconocidas a otras personas que en escencia y por definición de Ley, son sus iguales. Esa circunstancia es suficiente para considerar la trasgresión del artículo 1.1 de la Convención Americana para los Derechos Humanos que, para los efectos del Estado mexicano, debe entenderse como una norma de carácter general ${ }^{23}$ cuyo contenido se extiende a todo el contenido del tratado, en el que el Estado mexicano se asume con la obligación positiva de respetar y garantizar el pleno y libre ejercicio de los derechos y libertades allí reconocidos sin discriminación alguna.

\section{GARANTÍA PROCESAL PARA VISIBILIZAR TODA LA INFORMACIÓN RELATI- VA A LOS SINDICATOS Y SUS CONTRATOS COLECTIVOS DE TRABAJO}

El sistema de planeación democrática de México no puede, constitucionalmente, concebirse integral sin la participación y el involucramiento de la totalidad de información confiable e incluyente que se produce en los sectores sociales del país. A partir de esta se recogen sus aspiraciones y demandas como parte de nuestra sociedad, para que sean incorporadas al Plan Nacional y sus Programas de desarrollo ${ }^{24}$; es así que le resulta una obligación positiva al Estado mexicano organizar una planeación democrática que imprima, entre otras cosas, dinamismo, competitividad, equidad y crecimiento a la economía, con miras a la independiencia y democratización política, social y cultural de la nación.

Bajo ese principio constitucional contenido en el mencionado artículo 26, no puede excluirse al sector productivo del país, sobre todo en un porcentaje tan abrumador, sin que con ello se trasgreda la señalada norma constitucional, con los consabidos efectos sobre los derechos humanos de las personas omitidas en el diseño de las políticas públicas en materia de productividad, competitividad y desarrollo económico. Esta afirmación es vertida en razón de que, como ya se ha establecido supralíneas, la micro y pequeña empresas y sus trabajadores constituyen por una parte el $99.6 \%$ del total de las empresas o fuentes de empleo del país y de otra parte conforman nada menos que el $89.9 \%$ de los empleos formales reconocidos oficialmente, significando con su actividad económica, en su conjunto, el 52\% del Producto Interno Bruto; es en estos dos estratos de empresa y no de manera exclusiva, en los que mayoritariamente se contrata a los trabajadores bajo el sistema de contratación individual, del cual, ninguna institución del

\footnotetext{
${ }^{23}$ Entiéndase en función del contenido del propio tratado.

${ }^{24}$ El texto del parrafo primero del artículo 26 de la Constitución Política de los Estados Unidos Mexicanos, dice: El Estado organizará un sistema de planeación democrática del desarrollo nacional que imprima solidez, dinamismo, competitividad, permanencia y equidad al crecimiento de la economía para la independencia y la democratización política, social y cultural de la nación.
} 
país conserva sistematización de registro confiable alguno, en especial respecto del número de contratos y modalidad de contración, o del monto del salario, sus incrementos o disminuciones, prestaciones extralegales o condiciones generales de trabajo, la certificación de habilidades de sus trabajadores o de los procesos de capacitación inicial; o respecto de estas empresas, sus planes de inversión, viabilidad en el corto, mediano o largo plazos, sector de la economía al que pertenecen, la diversificación de sus financiamientos, sus fortalezas o debilidades, por señalar algunos de los datos más importantes.

La Ley Federal del Trabajo define a la empresa en su artículo 16 como la unidad económica de producción o distribución de bienes o servicios, y si bien en materia recaudatoria se le distingue por estratos, en función del principio de proporcionalidad; para los efectos procesales de la materia laboral, no existe proporcionalidad en ese aspecto y se le tasa con la misma regla, tratándose del patrón, por lo que se le arrojan cargas probatorias por igual, tratándose de micro o de gran empresa. No obstante, respecto del artículo 26 constitucional, el Estado implementa en la práctica una exclusión que desde luego surte sus impactos indirectos en los trabajadores de dichas fuentes de empleo y desde luego también vienen los impactos remotos en el conjuto de la sociedad, al repetirse este fenómeno a lo largo de toda la República mexicana. Esta exclusión, consistente en no disponer de la información confiable de las actividades de contratación individual, salario, condiciones interiores de trabajo, prestaciones, certificación de habilidades, procesos de capacitación inicial, etc., de los trabajadores de estas empresas; repercute en un diseño de políticas públicas laborales por lo menos incompleto, cuando no erróneo y por ello incapaz de revertir un daño que se ha convertido en estructural y que es potenciador de la desigualdad social.

En el diseño legislativo nada impide al Estado incluir a todas las personas en el sistema de planeación democrática y no restringir de manera fáctica al contenido del artículo 364 bis de la Ley Federal del Trabajo vigente; sin embargo, aunque nada impide que el resto de los trabajadores sean incluidos, son los usos y costumbres derivados de una larga e invicta tradición de exclusión e invisibilización del trabajador que, desde luego, rebasa la reforma laboral de 1970 y que se extiende hasta los orígenes de la colonia. A ese respecto y tras la reforma constitucional en materia de derechos humanos promulgada el 10 de junio de 2011, la exclusión se ha concebido como una forma de desigualdad, de discriminación ${ }^{25}$ misma que al encontrarse prohibida en la actual etapa de evolución del derecho internacional, del cual el Estado mexicano forma parte vinculante; el principio de igualdad y no discriminación se concibe ahora como parte del dominio del ius cogens y sobre este, se cimenta toda la estructura jurídica del orden público nacional e internacional que permea en todo el ordenamiento jurídico de México.

Bajo esta lógica jurídica, toda práctica en sentido contrario se entiende como promotora de la desigualdad y como una forma de resistencia a organizar todo el aparato gubernamental, y en general todas las estructuras a través de las cuales se manifiesta el poder público en su ejercicio cotidiano; pues la obligación del Estado mexicano es la de garantizar y asegurar jurídicamente el libre y pleno ejercicio de los derechos humanos y libertades reconocidos en el bloque de constitucionalidad. A ese respecto tal vez la Corte Interamericana de los Derechos Humanos no lograría que se garantice indemnizar — desde que se encuentra vigente la actual Ley Federal del Trabajo- a todos los lesionados excluidos de manera directa, indirecta y remota en el goce de sus libertades y derechos conculcados y que le permitan sin restricciones acceder a la dignidad humana; pues han pasado varias generaciones bajo ese yugo derivado de distinción de tratos

${ }^{25}$ Corte IDH. Caso Atala Riffo y niñas Vs. Chile. Fondo, Reparaciones y Costas. Sentencia de 24 de febrero de 2012. Serie C No. 239. 
normativos que oprimen a la contratación individual en México; pero sin duda que si resulta procedente la corrección inmediata de tal deficiencia, para que en lo sucesivo se eviten las consecuencias de una violación que se tornó estructural por prácticas atribuibles al Estado mexicano $^{26}$, pues toda práctica regresiva, solo puede concebirse, cuando se origina en una profunda justificación en los principios del bloque de constitucionalidad, lo que en el caso no se actualiza.

\section{Prohibición de discriminación}

El Estado mexicano debe abstenerse de materializar acciones destinadas de manera directa o indirecta, a propiciar situaciones de discriminación, en cualquiera de sus modalidades, ya sea de derecho o de hecho. Se encuentra en la obligación actual de adoptar medidas positivas para revertir o cambiar situaciones discriminatorias toleradas o consentidas existentes, en perjuicio de determinado grupo de personas, respecto de las cuales, se debe preservar el deber de protección. En este sentido una restricción debe considerarse la excepción y no la norma, ello siempre que al decretarse se encuentre razonable y objetivamente dirigida a proteger el bienestar general.

El término distinción se emplea válidamente hablando de tratamientos en el texto de la Ley, para lo jurídicamente admisible, en virtud de ser razonable y objetivo. El término discriminación se utiliza para hacer referencia a lo inadmisible, por violar los derechos humanos. Por tanto, siempre se utilizará el término discriminación para hacer referencia a toda exclusión, restricción o privilegio que no sea objetivo y razonable, que redunde en detrimento de los derechos humanos.

Podemos decir que la restricción en el texto de la Ley, es una de las peores formas de discriminación, y es carácterística de los regímenes dictatoriales que otorga para las personas tratos diferentes, sin que exista una justificación en el bloque de constitucionalidad. Implica pues, una descarada falta de objetividad y razonabilidad en la norma, por lo que resulta desproporcional y totalmente injustificada. La restricción solo puede existir de manera razonable y objetiva, cuando excepcionalmente se decreta para proteger a la sociedad de un mal mayor, por lo que no debería ser común encontrarla en el texto de la Ley.

La Corte IDH ha sido enfática en definir que el derecho internacional de los derechos humanos no solo prohíbe políticas y prácticas deliberadamente discriminatorias, sino también aquellas cuyo impacto sea discriminatorio contra ciertas categorías de personas, aun cuando no se pueda probar la intención discriminatoria ${ }^{27}$. De esta manera podemos sostener que el derecho a la igualdad y no discriminación se produce también ante situaciones y casos de discriminación indirecta reflejada en el impacto desproporcionado de normas, acciones, políticas o en otras medidas que, aun cuando sean o parezcan ser neutrales en su formulación o tengan un alcance general y no diferenciado, produzcan efectos negativos para ciertos grupos vulnerables, grupos de personas o en lo individual.

A ese mismo respecto, el Tribunal Europeo de Derechos Humanos ha establecido que cuando una política general o medida tiene un efecto desproporcionado perjudicial en un grupo particular, esta puede ser considerada discriminatoria aun si no fue dirigida específicamente a ese grupo. Es así que podemos afirmar que el principio de derecho imperativo de protección igualitaria y efectiva de la ley y no discriminación, obliga de manera efectiva al Estado mexicano

\footnotetext{
${ }^{26}$ Corte IDH. Caso Acevedo Buendía y otros Vs. Perú. Excepción Preliminar, Fondo, Reparaciones y Costas. Sentencia 01 de julio de 2009. Serie C No. 198, Párrafo 103.

27 Corte IDH. Caso Nadege Dorzema y otros Vs. República Dominicana. Fondo Reparaciones y Costas. Sentencia de 24 de octubre de 2012. Serie C No. 251.
} 
de abstenerse de producir regulaciones discriminatorias o que tengan efectos discriminatorios en los diferentes grupos de una población al momento de ejercer sus derechos.

El Comité de Derechos Económicos, Sociales y Culturales ha reconocido el concepto de la discriminación indirecta. Este concepto implica que una norma o práctica aparentemente neutra, tiene repercusiones particularmente negativas en una persona o grupo de personas con unas características determinadas. Al mismo tiempo el Protocolo de San Salvador, en su artículo primero, establece a México la obligación de adoptar las medidas necesarias tanto en su orden interno como mediante la cooperación internacional, especialmente económica y técnica, hasta el máximo de los recursos disponibles y tomando en cuenta su grado de desarrollo, a fin de lograr progresivamente, y de conformidad con la legislación interna, la plena efectividad de los derechos que se reconocen en el Protocolo. De igual manera en el artículo $2^{\circ}$ del Protocolo, se compromete a adoptar dispocisiones legislativas en su derecho interno para garantizar todos los derechos a todas las personas.

Es el artículo 1.1 de la Convención el que establece una prohibición de discriminación al Estado mexicano y el artículo 29 de la propia Convención establece cómo debe interpretarse dejando claro que a) ningún Estado parte puede suprimir los derechos y libertades que han sido ya reconocidos; b) tampoco puede limitar libertades y derechos que hayan sido reconocidos; c) tampoco puede excluir derechos y garantías inherentes al ser humano o que deriven de la forma democrática representativa de gobierno; d) excluir o limitar el efecto que pueda producir la Declaración Americana de Derechos y Deberes del Hombre y otros de la misma naturaleza.

\section{Criterios de objetividad y razonabilidad}

Ya se estableció que no toda diferencia de trato puede ser considerada discriminatoria, sino solamente aquella que se base en criterios que no puedan ser racionalmente apreciados como objetivos y razonables; es decir, cuando no persigue un fin legítimo y no existe una relación razonable de proporcionalidad entre los medios utilizados y el fin perseguido.

En materia de trabajo el Estado no se obliga a proveer y garantizar un empleo a cada trabajador, pero sí se encuentra en la obligación positiva de ser el rector del desarrollo económico nacional ${ }^{28}$, de generar las condiciones adecuadas para que la inversión sea equilibrada con el empleo; asimismo, al Estado le corresponde la obligación de vigilar que el empleo se desarrolle en condiciones de dignidad y que los productos y servicios sean de calidad o socialmente útiles y competitivos con el fin de garantizar un desarrollo económico sustentable para todas las personas; en tanto que al trabajador le corresponde la obligación de capacitarse y perfeccionar sus destrezas de manera que pueda asegurar un nivel de vida conveniente para su familia" ${ }^{29}$; por su parte, el patrón se obliga a desarrollar su inversión mediante actos lícitos, bajo la protección que por ampliación del concepto persona, le otorga el artículo $1^{\circ}$ constitucional, así mismo se encuentra obligada de respetar la debida diligencia en materia de los derechos humanos de las personas bajo su subordinación y en todas sus actividades o como consecuencia de sus operaciones $^{30}$.

Asimismo, en casos de tratos diferentes desfavorables, cuando el criterio diferenciador se corresponde con uno de aquellos protegidos por el artículo 1.1 de la Convención que aluden a) rasgos permanentes de las personas de los cuales estas no pueden prescindir sin perder su

\footnotetext{
${ }^{28}$ Artículo 25 de la CPEUM.

${ }^{29}$ Artículo XIV de la Declaración Americana de los Derechos y Deberes del Hombre.

30 ONU: Principios Rectores sobre las Empresas y los Derechos Humanos. Oficina del Alto Comisionado.
} 
identidad; b) grupos tradicionalmente marginados, excluidos o subordinados y, c) criterios irrelevantes para una distribución equitativa de bienes, derechos o cargas sociales; la Corte se encuentra ante un indicio de que el Estado ha obrado con arbitrariedad.

Una premisa y característica de la contratación laboral, ya sea colectiva o individual, es la subordinación, elemento jurídico que distingue al contrato de trabajo respecto de cualquier otra prestación de servicios; ese elemento coloca al trabajador individual en el inciso b), mencionado en el párrafo anterior, respecto del cual el Estado mexicano, en términos del artículo 1.1 de la Convención, se encuentra obligado a proteger de manera preferente de la discriminación $y$, por lo cual, no debe actuar con arbitrariedad.

Así, el trato que el Estado mexicano debe dar a todos los trabajadores debe ser igualitario, debe por lo tanto existir trasversalidad en el acceso a la igualdad jurídica, y conforme al artículo 1.1 de la Convención, por ello no deben permitirse tratos discriminatorios motivados por cualquier condición social, incluyendo una creada por el propio legislativo; como se plantea en la identificación de categorías sospechosas contenidas en todo el título séptimo denominado de las relaciones colectivas de trabajo, que se contiene en la Ley Federal del Trabajo, que de suyo se debe corresponder con los principios de universalidad, interdependencia, progresividad o indivisibilidad y desde luego otorgar la protección más amplia a todas las personas destinatarias de la norma, para que dicha norma encuentre en su contenido, objetividad y razonabilidad; y no todo lo contrario al restringirla sin fundamento a solamente a un arquetipo de trabajador; pues siendo ese el caso, ¿en qué significación de derecho humano quedan quienes libremente eligen no pertenecer a una asociación sindical?

\section{Conclusiones}

La razonabilidad como principio del derecho se significa como un instrumento que permite interpretar, dirigir o pragmatizar al legislativo en la creación de las normas; también funge como integrador, en tanto que proporciona criterios de solución en caso de resolver la existencia de una laguna en la Ley; también funge de manera limitativa, ya que establece límites al ejercicio de determinadas facultades; asimismo opera también como fundamento de los ordenamientos, por cuanto que legitima o en su caso, reconoce en su validez, otras fuentes de derecho; también es sistematizadora del orden jurídico. Sin el principio de razonabilidad sería imposible proveer de proporcionalidad lógica entre los medios y los fines de una norma, para que sea considerada legítima. Puede decirse entonces que un control de razonabilidad debe incluir el examen relativo a la afectación de los derechos humanos, para cumplir con la finalidad de máxima eficacia de la Constitución, por el cual se armonizan los principios de universalidad, interdependencia, indivisibilidad y progresividad; por lo que debe entenderse que los derechos no deben encontrarse en conflicto, ni deben postergarse, pues a quien se le reconoce un derecho, se le reconoce su protección.

La objetividad es una especie jurídica de la independencia, supone el previo conocimiento que motiva la toma de una o todas las decisiones; en el legislativo entraña un profundo conocimiento no solo sobre el derecho, sus principios, sino sobre la moralidad de la norma, pues en el contenido de la norma lleva implícita no solamente la ética del legislador, sino el previo examen de interdependencia, universalidad, indivisibilidad y progresividad, para evitar que la norma entre en conflicto con otras o con principios que a la postre puedan anularla.

Los sub-principios del principio de proporcionalidad, someten a la Ley Federal del Trabajo, y en el caso de estudio al título séptimo denominado de las relaciones colectivas de trabajo, al 
sub-principio de idoneidad, por el cual se puede establecer que el título séptimo denominado de las relaciones colectivas de trabajo, tenga o no, un fin constitucionalmente legítimo y que la afectación, exclusión u omisión de derechos fundamentales sea adecuada para conseguir el fin constitucionalmente legítimo o si dicha afectación, exclusión u omisión se apoya en la convencionalidad.

En todo caso la afectación, exclusión u omisión debe servir para promover, fortalecer o ayudar a conseguir el fin constitucional legítimo de la medida, pues como se ha dicho supra líneas, estas constituyen la excepción, pero nunca la norma cotidiana, si son creadas para prevenir a los destinatarios de la norma de un mal mayor. En todo caso debería ser de carácter temporal claramente definido en el cuerpo de la Ley.

Bajo la lupa del sub-principio de necesidad, la norma que otorga trato diferenciado a los trabajadores sujetos a las relaciones colectivas de trabajo, respecto de los que se encuentran sujetos a las relaciones individuales de trabajo, supone que dicha medida plasmada en la Ley, sea estrictamente indispensable, porque es la menos gravosa entre otras alternativas. Supone un estudio previo de la eficiencia y eficacia de las alternativas disponibles para determinar el costo beneficio de cada una de ellas; en el caso supone determinar bajo datos duros, el número de trabajadores sujetos a cada una de las formas de contratación - colectiva e individual- en el universo de la población económicamente activa con empleo formal; sus ingresos -incrementos y decrementos-, si son gravables o no, y su aporte en términos del artículo 31, fracción IV de la Constitución en armonía e interdependencia con los también constitucionales artículos $1^{\circ}$, $4^{\circ}, 5^{\circ}, 25^{\circ}, 26^{\circ}, y 123^{\circ}$, mediante los cuales se pueda determinar además el porcentaje de trabajadores que corresponden a los diferentes estratos de empresa que el estado tiene reconocidos para entre otros efectos, el tributario ${ }^{31}$, de acuerdo con el caso concreto. Así como la información disponible que conforme al artículo 26 constitucional tiene el Estado mexicano tanto de los trabajadores contratados por la vía colectiva, como de los contratados por la vía individual; aunque ello solo servirá para confirmar que el fin legítimo de dar la protección constitucional a todas las personas no puede ser regresivo, sino progresivo, pues al final deberá elegirse la alternativa que no lastime a más derechos fundamentales.

El subprincipio de proporcionalidad, en sentido estricto, pretende establecer cuál de los intereses en conflicto jerárquicamente iguales en abstracto, tiene mayor peso en el caso concreto, al efecto se deben realizar dos estudios, uno normativo y otro de naturaleza empírica; el primero se ocupa de establecer el lugar que los derechos fundamentales tutelados tienen en el conflicto, es decir, si existen principios en conflicto o si se trata solamente de normas en conflicto, para determinar igualmente los niveles de intensidad con los que la preferencia por un derecho fundamental pueda afectar a la norma o a los derechos fundamentales en conflicto.

Como se sabe, los derechos fundamentales no se encuentran unos por encima de otros, sino que se requiere del estudio casuístico para establecer la prevalencia que, en definitiva, no anula al que no resulta prevalente, sino que permite la subsistencia de ambos prima facie. Así el nivel de intensidad o afectación en los derechos fundamentales, en el análisis normativo, se mide en lo cuantitativo de la afectación al derecho fundamental concreto; en el presente caso, no se

${ }^{31}$ DOF: 30 de junio del 2009. Acuerdo General de la Secretaría de Economía y el Sistema de Administración Tributario. 
encontró conflicto alguno de principios fundamentales o convencionales, sino únicamente en la norma jurídica o regla.

En el estudio empírico, lo que importa es medir la intensidad de la intervención que puede ser leve media o grave; y, por otra parte, se mide el beneficio empírico que se reportan en relación con el otro derecho fundamental en colisión, de lo que se logra determinar que la norma o conjunto de ellas que se contienen en el capítulo séptimo, denominado de las relaciones colectivas de trabajo, entra en colisión con el tratamiento que previamente le otorga la ley a los demás trabajadores, los cuales son contratados por elegir en libertad, no pertenecer a una asociación sindical. De este modo, se hace visible en la Ley, una restricción de derechos que en la práctica resulta profundamente lesiva para una mayoría del $89.9 \%$ del total de los trabajadores formales en México.

Podemos establecer así que tratándose de reglas, según Robert Alexy:

- Cuanto mayor sea la importancia material de un principio constitucional dentro de la Constitución o en la Sociedad, mayor será su peso en la Ponderación (peso abstracto). Por ello el peso abstracto de hacer válidos los principios constitucionales para todo el universo de trabajadores formales, arrojará un valioso peso de ponderación.

- Cuanto más intensa sea la intervención en el derecho fundamental, mayor será el peso del derecho intervenido en la ponderación. En esa proporción, cuanto más intensa la realización del principio que fundamenta la intervención legislativa, mayor será su peso en la ponderación (peso concreto). Por ello, el peso concreto de la ponderación, de ampliarse el contenido de los derechos ahora reservados para la contratación colectiva haciéndolos extensivos a toda la contratación individual, será de amplias dimensiones.

- La intensidad en la intervención en el derecho fundamental depende del significado que tenga la intervención legislativa dentro del ámbito normativo, en cuanto a la realización de las facultades de la persona liberal, de la persona democrática y del individuo del Socialismo. La significación de la intervención en la ampliación de los derechos fundamentales genera un espectro amplio de beneficios a todas las personas que, desde nuestra perspectiva rebasa ideologías.

- La intensidad de la realización del fin mediato del legislador depende de la función que el fin inmediato desempeñe para la satisfacción de los intereses individuales o colectivos que el fin mediato garantiza. Sin duda, quienes históricamente se han protegido de esta exclusión legal tienen altas probabilidades de no sentirse aparejados con los trabajadores de contratación individual; ello no afecta las condiciones de trabajo o prestaciones que en caso contractual se tengan en el contrato, sino los tratamientos legislativos diversos que contiene la ley.

- La intensidad de la intervención en el derecho fundamental depende de la eficacia, rapidez, probabilidad, alcance y duración con los que la intervención legislativa afecte negativamente a la posición de derecho fundamental. No se tiene prevista una afectación negativa, desde el punto de vista jurídico, con la propuesta.

- La intensidad de la realización del fin mediato del legislador depende de la rapidez, eficacia, probabilidad, alcance, y duración con los que la intervención legislativa contribuye a obtener el fin inmediato del legislador. La generalización del reconocimiento del derecho a 
una vida digna para todas las personas en el texto de la Ley asegura la consecución de los fines inmediatos y futuros del legislador.

En todo caso, siempre debe tenerse en cuenta los precedentes, la realización del principio más democrático y la dignidad humana.

\section{Bibliografía}

Alexy, Robert (2007), Teoría de los Derechos Fundamentales, trad. Carlos Bernal Pulido, $2^{\mathrm{a}}$ Edición, Madrid, Centro de Estudios Políticos y Constitucionales, El derecho y la Justicia.

Amanor, Boadu, Vincent (1999), Strategic Alliances in Canadian Agri-Food Industries, Canada, George Morris Centre, Guelph.

Caso Mininuma. EL CASO "MININUMA": UN LITIGIO ESTRATÉGICO PARA LA JUSTICIABILIDAD DE LOS DERECHOS SOCIALES Y LA NO DISCRIMINACIÓN EN MÉXICO. UNAM. Revistas UNAM. Revista de la Facultad de Derecho de México. Tomo LXIX, Número 274 (mayo-agosto 2019).

CEDIP, UNAM et. al. (2015), Diario de sesiones de las Cortes Generales y Extraordinarias de Cádiz, proceso de creación de la Constitución Política de la Monarquía Española de 1812, vigente en las provincias mexicanas, México.

Corte Interamericana de Derechos Humanos, [en línea], disponible en: http://www.corteidh. or.cr

Convención de Viena sobre el Derecho de los Tratados, Parte III relativa a la Observancia, aplicación e interpretación de los Tratados, Sección Primera, de la Observancia de los tratados.

Constitución Política de los Estados Unidos Mexicanos.

Convención Americana para los Derechos Humanos.

Padrón Inamoratto, Mauricio et. al. (2017), No todo el trabajo es empleo. Avances y desafíos en la conceptuación y medición del trabajo en México, Colegio Mexiquense A.C., UNAM-IIJ.

Peces-Barba Martínez, G. (1995), Curso de Derechos Fundamentales, Teoría General, colab. Rafael de Asís Roig, Carlos R. Fernández Lieza, Ángel Llamas Cascón. Colección 3, Universidad Carlos III de Madrid.

Protocolo Adicional a la Convención Americana sobre Derechos Humanos en materia de Derechos económicos, Sociales y Culturales (Protocolo de San Salvador).

Reynoso Castillo, Carlos (2015), Los derechos humanos laborales. Derechos Humanos y Poder Judicial, UAM. (1990), El despido individual en América Latina, México, UNAM. 
Sánchez-Castañeda, Alfredo et. al. (2011), "La Subcontratación: un fenómeno global. Estudio de legislación comparada”, Revista Latinoamericana de Derecho Social, México, UNAM.

(2016), "Avances de la reforma constitucional respecto al derecho de acceso a la información en sindicatos", Revista Jurídica UNAM, INAI, [en línea], disponible en: www. juridicas.unam.mx.

(2006), Las transformaciones del derecho del trabajo, México, UNAM.

Tesis 1a./J125/2017, Semanario del PJ, SJF y su Gaceta Libro 49, Décima época, Primera Sala, diciembre de 2017, Tomo I., pág. 121. Número 2015679. Jurisprudencia Constitucional. Texto: Derecho Humano a la Igualdad Jurídica. Reconocimiento a su dimensión sustantiva o de hecho en el ordenamiento jurídico mexicano.

Tesis número 2008792. P. IV/2015, Semanario del PJF, Semanario Judicial de la Federación, Gaceta del Semanario Judicial de la Federación. Libro 17, (10a.), Pleno, Décima Época, abril de 2015, Pág. 159. Rubro. "CONFLICTOS COLECTIVOS DE NATURALEZA ECONÓMICA. EL AMPARO PROMOVIDO EN CONTRA DEL LAUDO QUE LOS RESUELVE, PERMITE AL JUZGADOR EXAMINAR NO SÓLO LOS ASPECTOS FORMALES DE ESA DECISIÓN, SINO INCLUSO, LA SITUACIÓN ECONÓMICA DE LA EMPRESA ACTORA". 